\section{AGRICULTORES FAMILIARES E CIENTISTAS: DIÁLOGO DE SABERES SOBRE AS VARIEDADES GRIOULAS DE MILHO NO ESTADO da paraĺba}

\author{
Maria José Ramos da Silva \\ Fillipe Silveira Marini \\ Aline Carneiro de Paula \\ Alexsandro Alves Coelho \\ Amaury da Silva dos Santos
}

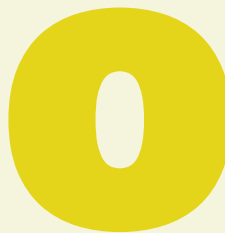

manejo de sementes crioulas pelos agricultores familiares é uma prática adotada para a conservação dos recursos genéticos locais e manutenção da vida. No estado da Paraíba, agricultores familiares têm como uma de suas estratégias para convivência com o clima semiárido a utilização de variedades crioulas, pois apresentam elevada estabilidade e resistência a estresses bióticos e abióticos em função de suas resiliências e adaptação a menores escalas de insumos artificiais. Variedades crioulas são aquelas mantidas pelos próprios agricultores ao longo de muitas gerações e, ao serem cultivadas e selecionadas por eles, adquirem características próprias de adaptação ao agroecossistema local (1).

A conservação dos recursos genéticos, vem sendo utilizada pelos agricultores familiares, há séculos, a partir da conservação in situ, metodologia estabelecida para a manutenção dos agroecossistemas produtivos, no qual, cultivam, selecionam e conservam espécies vegetais, com o uso de técnicas agrícolas menos agressiva à natureza (2).

Embora o uso de variedades crioulas seja uma característica da agricultura familiar no estado da Paraíba e em outras regiões no Brasil, essa prática está cada vez mais ameaçada, seja pela distribuição de sementes de cultivares comerciais por meio de políticas públicas - o que vem causando a contaminação e perda de sementes locais -, ou pelas práticas de intensificação da agricultura com dependência de variedades comerciais (híbridas e transgênicas), de irrigação e da utilização de insumos agroquímicos. Isso, sem dúvida, está provocando a deterioração da saúde humana e da qualidade ambiental, ameaçando também a manutenção da agrobiodiversidade (3). Assim, existe um crescente aumento no interesse em se conhecer as variedades crioulas e saber como e onde estão sendo conservadas pelos agricultores (4).

Outra estratégia importante desses agricultores é o intercâmbio frequente de materiais genéticos, seja em feiras e mercados, em eventos envolvendo agricultores e também em visitas informais entre parentes e vizinhos. Este fato é bem exemplificado por Gazzola \& Schneider (5), quando relatam os momentos em que uma família perde sua semente e a busca com vizinhos. Essa busca normalmente desencadeia processos de trocas ou mesmo empréstimos que podem ser pagos (ou não) de diferentes formas, inclusive com outro tipo de semente. Nesse processo de troca, nomes de materiais genéticos podem se perder e serem alterados sistematicamente, ou mesmo acabarem recebendo nomes iguais mesmo sendo geneticamente diferentes. No entanto, os próprios agricultores guardiōes conhecem e distinguem os seus materiais de outros com o mesmo nome, uma vez que este foi selecionado para as suas próprias condições, porém mantendo muitas das características do genótipo (material genético) comum. Mais precisamente no estado da Paraíba, a variedade de milho Jaboatão ou Jabatão é bastante disseminada em diferentes territórios e ambientes, assim como existe um grande número de variedades crioulas com diferentes nomes, porém com características semelhantes a ela.

O DIÁLOGO DE SABERES: CIENTíFICO E TRADICIONAL Dentro da perspectiva da construção do conhecimento agroecológico, exige-se que sejam estabelecidos canais de diálogo entre o conhecimento dos agricultores, dos técnicos e dos cientistas, por meio de processos participativos. A participação social pode ocorrer de diversas formas e existe um conjunto crescente de técnicas e dinâmicas que permitem a sua materialização, desde a consulta nos processos de intervenção na comunidade até a incorporação dos saberes e práticas dos agricultores nos processos de pesquisa, como na pesquisa participativa (6).

Diferindo da pesquisa agronômica convencional, a pesquisa ou experimentação agroecológica tem como premissa a participação de agricultores em todas as suas fases, ou seja, desde seu planejamento até a avaliação e a divulgação dos resultados, sem, no entanto, em nenhum momento, desvalorizar o rigor científico. A pesquisa participativa tem como um de seus propósitos a construção de conhecimentos a partir de saberes (científico e empírico) nos quais, conjuntamente, são identificados os avanços e desafios para determinar as possíveis ações que possam contribuir com o processo de construção social da comunidade. Segundo Leitgeb e colegas (7), os agricultores exercem papel de relevância na construção do conhecimento, difusão e apropriação através de experimentação e troca dinâmica em espaços coletivos, na perspectiva de melhoria da gestão dos recursos genéticos disponíveis em sua comunidade. Assim, agricultores e cientistas possuem diferentes saberes e habilidades, sendo que cada um deles complementa o outro, de tal forma que quando trabalham em conjunto produzem melhores resultados do que se obtidos de forma isolada (8).

As experimentações realizadas pelos próprios agricultores ganham grande dimensão na domesticação e melhoramento de plantas, que se iniciou há, pelo menos, 10 mil anos, quando os humanos se tornaram agricultores. Enquanto as experiências acadêmicas com o melhoramento de plantas iniciaram-se apenas há cerca de 100 anos. E, mesmo com o poder econômico das grandes corporações do agronegócio, estima-se que, atualmente, nos países em desenvolvimento cerca de $60-90 \%$ das variedades de plantas utilizadas são 
frutos da inovação e seleção dos próprios agricultores (8). Assim, vislumbra-se que a pesquisa para o melhoramento de plantas deveria estar intimamente ligada aos agricultores, considerando os seus próprios indicadores e o "olhar" do agricultor, não limitando-se apenas as características agronômico-produtivistas.

Porém, em muitos casos, segmentos da pesquisa e extensão rural negligenciam a importância dos agricultores e de suas variedades tradicionais. Ao mesmo tempo, nem todas as comunidades dominam essa técnica de resgatar, caracterizar, selecionar e conservar os recursos genéticos disponíveis. E o envolvimento dos agricultores em pesquisas participativas com sementes crioulas é vital. Witcombe e co-autores (9) relataram que o processo de seleção das variedades deve ocorrer na comunidade, de forma participativa, pois permite aos agricultores acompanharem todo o processo de avaliação e melhor identificação das características consideradas desejáveis. Assim, envolver os agricultores na identificação de variedades é particularmente importante para a seleção das variedades mais adaptadas à sua realidade local (10).

PESQUISAS COM A(S) VARIEDADE(S) CRIOULA(S) DE MILHO JABOATÃO No estado da Paraíba vem sendo desenvolvida metodologia participativa para caracterização de variedades crioulas com o propósito de conservar e valorizar a sua diversidade, além de empoderar os agricultores no manejo dos recursos naturais para a construção de um ambiente mais equilibrado, o que infere autonomia às famílias na reprodução de suas sementes e, consequentemente, uma maior relação na produção/consumo.

Esse trabalho teve por objetivo avaliar exemplares coletados da variedade de milho Jaboatão (também chamado por Jabatão) e outras variedades crioulas, por meio de avaliação participativa, visando identificar genótipos superiores, nos ambientes estudados, e identificar também possíveis divergências e similaridades fenotípicas entre essas variedades, para conservar e valorizar a sua diversidade. Procurou-se, ainda, valorizar os agricultores no manejo das sementes crioulas, buscando a construção de um ambiente mais sustentável e conferindo às famílias autonomia na produção e posterior segurança alimentar.

O desenvolvimento do estudo aconteceu mediante a realização de reuniōes com a Rede Sementes da Paraíba, onde foi apresentada a demanda sobre os diferentes nomes da variedade Jaboatão e de outras muito parecidas, porém com nomes distintos. Em uma dessas reuniōes, foram determinados os locais onde seriam executadas as ações de pesquisa assim como as variedades que seriam testadas e os seus guardiões. Assim, o trabalho foi desenvolvido no assentamento Acauã do município de Aparecida (experimento I) e no campus III de Bananeiras (experimento II) do Centro de Ciências Humanas Sociais e Agrárias (CCHSA) da Universidade Federal da Paraíba (UFPB).

Os materiais genéticos utilizados foram variedades crioulas de genótipos com diferentes denominações (Adelaide, Bom e Jaboa- tão) de agricultores guardiōes, porém com características fenotípicas semelhantes à variedade Jaboatão. As sementes de cada variedade foram coletadas a partir de visitas às unidades produtivas de agricultores familiares da região.

Os ensaios foram conduzidos nas condições usualmente adotadas pelos agricultores com plantio em cova, capina manual e utilização de extrato de Nim para controle das principais pragas, sem utilização de calagem e adubação química.

Em reuniōes prévias, agricultores com base em suas experiências e conhecimentos adquiridos na cultura de milho, definiram os indicadores para avaliação qualitativa e participativa das variedades, que ocorreram no ponto verde, que é a fase de maturação da espiga, e no ponto seco. Realizou-se a avaliação quantitativa considerando-se produção de palha da planta $(\mathrm{kg} / \mathrm{ha})$ e produção de grãos $(\mathrm{kg} / \mathrm{ha})$ quando as espigas estavam aptas para a colheita de grãos.

Foram convidados agricultores familiares dos municípios que fazem parte da dinâmica de conservação das sementes crioulas da Articulação do Semiárido Paraibano (ASA-PB), que avaliaram os genótipos de milho com base em suas experiências e conhecimentos, atribuindo notas em ordem crescente, que representou a ordem de preferência para cada variável/característica, sendo: 1 fraco; 2 médio; 3 bom; e 4 ótimo. As variáveis analisadas foram: tamanho da planta (TP); produção de palha da planta e da espiga (PP); formação da espiga (FE); enchimento das espigas (EE) e; visão geral da planta (PG).

$\mathrm{Na}$ ocasiāo, os convidados foram divididos em grupos. Cada grupo tinha a presença de um técnico, que era imparcial e tinha o papel de auxiliar na avaliação, no sentido de fazer as anotações e manter uma sequência, evitando que uma variedade fosse avaliada várias vezes. A avaliação participativa deixou os avaliadores livres para expor características produtivas relevantes para as unidades familiares, o que permitiu uma melhor interação com os pesquisadores desmitificando a crença de incapacidade a qual os agricultores eram classificados no período de modernização da agricultura, conforme menciona (12): "o reconhecimento dos diversos conhecimentos é um componente essencial para manter vivos diferentes sistemas produtivos".

Os resultados foram submetidos à análise de variância em software estatístico Assistat versão 7.7 (11), para o teste F a 5\% de probabilidade, sendo as médias comparadas pelo teste Tukey. Todas as variáveis foram submetidas à transformação dos dados pela fórmula $<\mathrm{X}=$ raiz quadrada de $\mathrm{x}>$.

$\mathrm{Na}$ avaliação realizada pelos agricultores no ensaio em Aparecida (PB), observou-se que a variedade de milho Bom do município de Patos foi bem avaliado para todas as variáveis, com exceção para o tamanho e produção de palha que foi notificado como médio, divergindo da variedade Jaboatão do município de Montadas, que foi notificado como fraco para todas as variáveis estudadas. As demais variedades foram atribuídas como médio na maior parte das variáveis, o que remete a semelhanças em suas características (Tabela 1). 
Esse resultado denota a heterogeneidade de comportamento típica das variedades crioulas, que tendem a se expressar positivamente ou negativamente para determinada característica. Verificou-se também que os resultados atribuídos pelos agricultores em espigas ainda verdes (ponto verde) das variedades de milho Jaboatão de Montadas e Bom de Patos se repetiram na avaliação quantitativa no ponto seco, o que mostra que cada ator e atriz envolvidos nesse processo possui domínio na seleção de variedades (Tabela 1).

Há de se ressaltar que, na concepção dos agricultores, uma variedade é considerada boa para semente quando apresenta espiga totalmente coberta por palha, fileiras retas de sementes e completas com ausência de carreira falhas ou "banguelas", como vulgarmente denominado pelos agricultores.

$\mathrm{Na}$ avaliação realizada pelos agricultores em Bananeiras (PB), observou-se que as variedades receberam atribuiçóes variadas com destaque para determinadas características. Podemos visualizar na Tabela 1 que o milho Jaboatão de Massaranduba, Alagoa Nova, Matinhas e Soledade foram considerados bons para as variáveis tamanho da planta e produção de palha no momento da avaliação no ponto verde, repetido no ponto seco para as variedades Jaboatão do município de Massaranduba (1). A contradição observada para alguns genótipos nos períodos seco e verde pode estar relacionada ao manuseio in loco das espigas, diferente do ponto verde, que utiliza o aspecto visual e o tato para apalpá-las e avaliá-las.

Ao avaliar o aspecto geral das plantas/espigas/grãos, observa-se que as variedades de milho Jaboatão de Casserengue, Bom de Cacimbas, Jaboatão de Remígio (2), Jaboatão de Matinhas e Adelaide do município de Soledade foram considerados médio e bom pelos avaliadores. As demais variedades Jaboatão de Remígio, de Massaranduba, de Montadas e de Alagoa Nova apresentaram maior oscilação nas notas, variando entre fraco, médio e bom. Nesse ensaio verificou-se que houve uma maior similaridade de comportamento das variedades de milho Jaboatão dos diferentes municípios e guardiōes. A semelhança entre as variedades foi observada também para a produção de grãos. Esse resultado pode estar relacionado à proximidade do local do ensaio com o local de adaptação dessas variedades, localizadas na região da Borborema. Por outro lado, as variedades de milho Bom e Adelaide são oriundas do Sertão e Cariri, respectivamente, e apresentaram comportamento semelhante às variedades Jaboatão.

Tabela 1 - Médias da avaliação participativa, no ponto verde (PV) mediante atribuição de notas 1-fraco; 2-médio; 3-bom e 4-ótimo para as variáveis: tamanho da planta (TP), produção de palha (PP), formação da espiga (FE), enchimento da espiga (EE), aspecto geral da planta (PG) e avaliação quantitativa no ponto seco (PS) para as variáveis: produção de palha e produção de grãos (kg/ha) no ensaio de milho de variedade crioulas, em Aparecida-PB e Bananeiras-PB no ano de 2013.

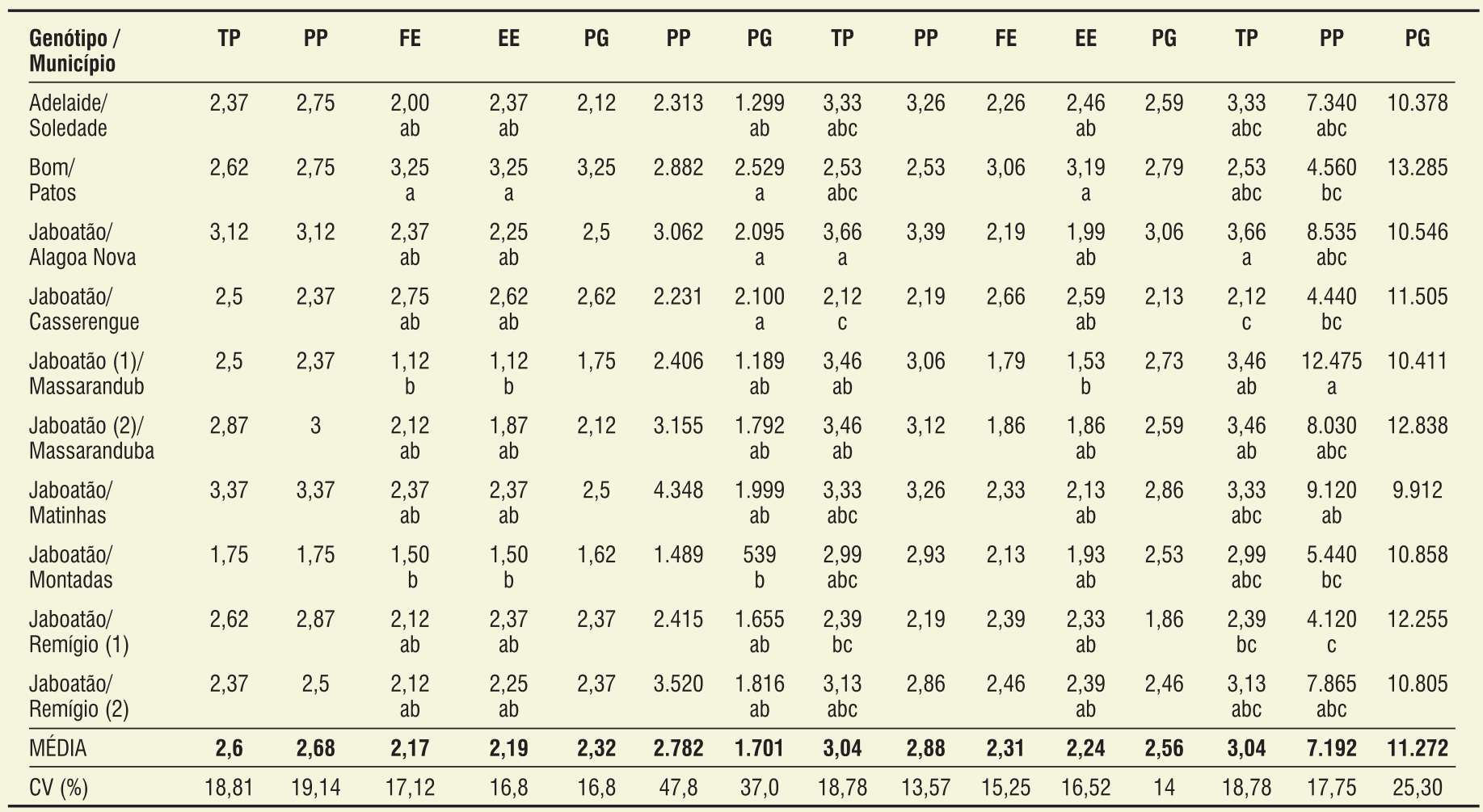

Médias nas colunas seguidas pela mesma letra não diferem entre si estatisticamente pelo Teste Tukey a $5 \%$ de probabilidade.. 
Considerando que a produção de palha é uma das características mais importantes para os agricultores que participaram dos ensaios, verifica-se que em Bananeiras as variedades que obtiveram melhores avaliações foram Jaboatão Alagoa Nova, Jaboatão Matinhas, Adelaide e Jaboatão Masaranduba 1. Ao comparar com a produção de palha (kg/ha) no mesmo ensaio, observamos algumas coincidências entre as de melhor desempenho, no caso Jaboatão Massaranduba 1 e Jaboatão Matinhas.

Com base em apenas dois ensaios em distintas regiōes, observa-se a grande diversidade de resultados. Mesmo sabendo que isso não é nenhuma novidade, verifica-se que, em alguns casos, as políticas públicas insistem que o semiárido é uma região única e que apenas uma variedade de milho atenda a toda a região, ignorando os próprios anseios dos agricultores. Muitas vezes, essas políticas direcionam ao agricultor sementes de variedades super precoces que produzem grãos em tempo curto, como estratégia para convivência no semiárido. No entanto, muitos desses agricultores estão mais preocupados em produzir palha para alimentar os seus animais, enquanto as sementes distribuídas originam plantas de baixo porte com pouca produção de palha. Este é apenas um exemplo que demonstra a necessidade de diálogo entre todos os atores envolvidos na agricultura familiar, onde todos ensinam e todos aprendem.

Maria José Ramos da Silva é mestre em ciências agrárias (agroecologia) pelo Centro de Ciências Humanas Sociais e Agrárias-CCHSA, da Universidade Federal da Paraíba (UFPB).Email: maryramos8@hotmail.com.

Fillipe Silveira Marini é agrônomo e doutor em produção vegetal e professor da UFPB. Email:fsmarini@yahoo.com.br.

Aline Carneiro de Paulaé mestranda em ciências agrárias pelo Centro de Ciências Humanas Sociaise Agrárias-CCHSA, da UFPB. Email: alinecarneiro_paula@hotmail.com. Alexsandro Alves Coelho égraduado em tecnologia em agroecologia pelo Instituto Federal de Educação, Ciência e Tecnologia da Paraíba, campus Sousa e agricultor experimentador do assentamento Acauã do município de Aparecida (PB).

Amaury da Silva dos Santos é agrônomo e doutor em produção vegetal e pesquisador da Embrapa Tabuleiros Costeiros.Email: amaury.santos@embrapa.br.

\section{REFERÊNCIAS}

1. Bellon, M. R.; Brush, S. B. "Keepers of maize in Chiapas, Mexico". Economic Botany, New York, v. 48, n.2, p. 196-209, 1994.

2. Nodari, R. O.; Guerra, M.P. “'A agroecologia:estratégias de pesquisae valores". Estudos Avançados, v. 29, n.83, p. 183-207, São Paulo, 2015.

3. Evenson, R. E.; Gollen, D. "Assessing the impact of the green revolution, 1960 to 2000". Science 300, 758-762. 2003.

4. Jarvis, D. I.; Zoes, V.; Nares, D.; Hodgkin, T. “On-farm management of crop genetic diversity and the Convention on Biological Diversity's programme of work on agricultural biodiversity". Plant Genet. Resour. Newslett. 138, 5-17. 2004.

5. Gazzola, M.; Schneider, S. "A produção da autonomia: os 'papéis' do autoconsumo na reprodução social dos agricultores familiares". Estudos Sociedade Agricultura, v.15, n.1, p. 89-122, Rio de Janeiro, 2007.
6. Santos, A. S.; Curado, F. F. "Perspectiva para a pesquisa agroecológica: diálogo de saberes". Aracaju: Embrapa Tabuleiros Costeiros, 2012, 20p. (Embrapa CPATC. Documentos, 172).

7. Leitbeg, F.; Funes-Monzote, F. R.; Kummer, S.; Vogl C. R. “Contribution of farmer's experiments and innovation to Cuba's agricultural innovation system". Renewable Agriculture and Food Systems 26: 354-367, 2011.

8. Hoffmann, V.; Probst, K.; Christinck, A. "Farmers and researchers: how can collaborative advantages be created in participatory research and technology development?". Agriculture and Human Values 24: 355-368, 2007.

9. Witcombe, J. R.; Joshia, A.; Goyal, S. N. " Participatory plant breeding in maize: A case study from Gujarat, India". Euphytica, v.130, p. 413422, 2003. DOI 10.1007/s10681-006-9333-y.

10. Dorward, P.; Craufurd, P.; Marfo, K.; Dogbe, W.; Bam, R. “Improving participatory varietal selection processes: participatory varietal selection and the role of informal seed diffusion mechanisms for uplandrice in Ghana".Euphytica, v.155, p.315-327,2007.DOI10.1007/ s10681-006-9333-y.

11. Silva, F. A. S. E.; Azevedo, C. A. V. de. Principal components analysis in the software assistat-statistical attendance". In: World Congress on Computers in Agriculture, 7, Reno-NV-USA: American Society of Agricultural and Biological Engineers, 2009.

12. Shiva, V. Biopirataria: a pilhagem da natureza e do conhecimento. Tradução: Laura Cardellini de Oliveira. Petrópolis, RJ: Vozes, 2001. 